\title{
Mbya reko e elementos urbanos: encontros dos Guarani Mbya com a cidade em contextos distintos de ocupação no Estado do Rio de Janeiro
}

\author{
Vicente Cretton Pereira
}

\begin{abstract}
Resumo: A partir de trabalho de campo em aldeias guarani mbya do estado do Rio de Janeiro, especialmente aquela que se localiza em perímetro urbano, na Região Oceânica da cidade de Niterói, procurei discutir a relação destes grupos indígenas com a cidade e categorias relacionadas. Situações observadas durante a pesquisa suscitaram uma série de questões sobre os motivos e expectativas que gravitam em torno da mobilidade de grupos (e indivíduos) guarani mbya: que critérios orientam a busca por novos lugares para se viver? Porque a escolha de um local urbano como destino do deslocamento? Quais as reações (interiores e exteriores ao grupo) que uma ocupação guarani em um meio urbano pode causar? A partir destes questionamentos procurei investigar como era conciliada, pelos diferentes sujeitos, a idéia de um povo (o "índio" genérico) visto, essencialmente, como "habitante das matas" ocupar um espaço urbano. Busquei entender também qual a importância dos aspectos "urbanos" no cotidiano dos Guarani Mbya, e como os significados envolvidos na categoria apareciam nos diferentes contextos. Na discussão procuro destacar as concepções cosmológicas mbya guarani em relação com o cotidiano dos sujeitos, levando em conta as trajetórias pela cidade e modos especificos de apropriação do "urbano".
\end{abstract}

Palavras-chave: Identidade indígena; ocupações urbanas; Guarani Mbya.

\begin{abstract}
Based on field work made at the guarani mbya indigenous villages of Rio de Janeiro state, specially the one which is located in urban perimeter, in the Região Oceânica of Niterói city, I intend to discuss the relations between this indigenous groups with the city and its related categories. Some situations observed during research development gave rise to a series of questions about reasons and expectations that gravitate around the mobility of groups (and individuals) guarani mbya: which criterions orientate the search for new places to live in? Which are the reasons that lead them to choose an urban place as destiny of the movement? Which reactions (inside and outside the group) a guarani occupation in the city may cause? I intended to investigate how was it possible the rise, by the different subjects, of the idea of a people (the generic "indio") perceived as "forest inhabitant" invading an urban space. I aimed to understand, as well, which was the importance of "urban" aspects in the everyday life of the Guarani Mbya, and how the meanings related to that category showed up in different contexts. With this discussion I intend to detach the mbya guarani cosmologic conceptions related with the the group's every day life, considering the trajectories in the city and specific ways of appropriation of the "urban".
\end{abstract}

Key-words: Indigenous identity; urban occupation; Guarni Mbya.

\footnotetext{
*Vicente Cretton Pereira é mestrando do Programa de Pós-Graduação em Ciências Sociais da Universidade do Estado do Rio de Janeiro (PPCIS/UERJ).
} 
Résumé: À partir de travail de champ dans des villages guarani mbya de l'état de Rio de Janeiro, spécialement celle qui se localise dans le périmètre urbain, dans la Région Océanique de la ville de Niterói, j'ai cherché à discuter la relation de ces groupes indigènes avec la ville et les catégories rapportées. Des situations observées pendant la recherche ont suscité une série de quéstions sur les raisons et des attentes autour de la mobilité de groupes (et personnes) guarani mbya : quels critères guident la recherche par des nouvelles places pour se vivre? Pour quoi le choix d'un lieu urbain comme destination du deplacement? Quelles sont les réactions (intérieurs et extérieurs au groupe) qu'une occupation guarani dans un moyen urbain peut causer? À partir de ces questionnements, $j$ 'ai interrogé comment était concilié, par les différents sujets, l'idée d'un peuple ( $l$ ' "Indien" générique), essentiellement vu comme "habitant des bois", qui occupe un espace urbain. J'ai cherché à comprendre aussi quelle est l'importance des aspects " urbains » dans le quotidien du Guarani Mbya, et comme les significations impliquées dans la catégorie apparaissaient aux différents contextes. Dans la discussion, je cherche à détacher les conceptions cosmologiques mbya guarani par rapport le quotidien des sujets, en considerant les trajectoires pour la ville et les manières spécifiques d'appropriation de l' "urbain".

Mots-clés : Identité indigène ; occupations urbaines; Guarani Mbya.

\section{Introdução: Questões, objetivos e método}

Empoleirado no alto de um esteio de eucalipto, ajudando Luciano, guarani mbya de 18 anos, a completar o telhado de sapê de uma oca em fase final de construção, perguntei se ele preferia a aldeia de Niterói (município próximo à cidade do Rio), onde residia no momento, ou a aldeia de Paraty Mirim (localizada na área rural de Paraty, sul do estado do Rio), onde havia morado por treze anos seguidos, antes de se mudar para a área litorânea fluminense. Ele, então, me respondeu, “aqui", e quando perguntei porque, falou: “aqui as coisas são mais pertinho. Você precisa comprar $1 \mathrm{~kg}$ de açúcar e é só andar até ali. Em Paraty, precisa pegar ônibus".

A resposta, que era por mim, até certo ponto, inesperada, suscitou uma série de questões sobre os motivos e expectativas que gravitam em torno da mobilidade de grupos (e indivíduos) guarani mbya: que critérios orientam a busca por novos lugares para se viver? Porque a escolha de um local urbano como destino do deslocamento? Quais as reações (interiores e exteriores ao grupo) que uma ocupação guarani em um meio urbano pode causar? A partir destes questionamentos procurei investigar como era conciliada, pelos diferentes sujeitos, a idéia de um povo (o "índio" genérico) visto, essencialmente, como "habitante das matas" ocupar um espaço urbano. Busquei entender também qual a importância dos aspectos "urbanos" para o cotidiano dos Guarani Mbya, e como os significados envolvidos na 
categoria apareciam nos diferentes contextos: na ocupação urbana (na cidade de Niterói - RJ), e nas aldeias localizadas em áreas de floresta abundante (na cidade de Paraty - RJ).

Desejo descrever de forma breve e sucinta sobre a natureza de minha entrada em campo, e ao meu ver, isto quer dizer, fundamentalmente, responder à seguinte pergunta: o que, inicialmente, podia eu trocar com os guarani mbya com quem procurava conviver? Isto é, que interesse mútuo poderia surgir e fazer com que conseguisse estabelecer com eles uma relação? Bom, a resposta, na ordem em que apareceram no trabalho de campo, é composta dos seguintes elementos: futebol, plantas e tabaco ${ }^{1}$. Num olhar retrospectivo, hoje, já com mais de um ano de trabalho, eu diria que sem estas três coisas eu teria tido bem mais dificuldades do que as já encontradas. Creio, então, que, a esta altura, devo narrar algumas situações emblemáticas que me permitem dizer o que estou dizendo.

Na primeira vez em que estive na aldeia, os jovens estavam envolvidos na construção de uma cerca. Fiquei meio "sem-cenário" ali, meio deslocado, sem puxar assunto, diante de meu próprio estranhamento perante à língua mbya, da qual não podia distinguir uma só palavra. Meu desconforto praticamente desapareceu quando chegou na aldeia um grupo escolar do IEPIC (colégio público de Niterói) que pediu pra entrevistar o Darci (o cacique da aldeia). Praticamente, tornei-me índio (creio que devido à minha aparência física) aos olhares dos alunos do IEPIC que até pediram para tirar foto comigo, certos de que eu era um "autêntico" guarani. Assim, acabei me enturmando no clima do trabalho (de brincadeiras, diversão e risadarias) e no próprio trabalho também. Fui ficando, pois me chamaram pra jogar futebol, logo que terminassem aquela tarefa. Desde então, procurava voltar à aldeia sempre no final de tarde, horário em que a "pelada" acontece diariamente.

Assim, o futebol atuou como uma primeira área de interesse comum entre eu e eles, e foi também, é claro, uma boa "desculpa" para voltar à aldeia outras vezes, já que ao final desta primeira partida o Darci me falou: "volta aí, e traz os amigos". Assim, foi minha presença constante no futebol que me abriu as portas para uma outra parte importante do diaa-dia da aldeia: o ritual da casa de reza (em guarani, opy), que também acontece diariamente, um pouco depois do futebol, no início da noite. Mas tratarei deste tema mais profundamente nos itens subseqüentes do texto.

Um outro fator que logo vislumbrei como um "ferramenta" de aproximação foi meu interesse pessoal por plantas e por qualquer coisa que se relacionasse com elas. Em minhas conversas eu gostava sempre de frisar este meu interesse, dizendo que podia trazer algumas 
mudas pra contribuir com a horta que já existia perto da entrada da aldeia. Sempre me falavam para trazer mesmo, então eu trazia: sementes compradas, catadas na floresta e até mudas de plantas que eu tenho em casa. Algumas vezes levei sementes que não sabia de que era, e então perguntava para eles. Nestas ocasiões sempre percebia um interesse meio que geral pela semente: todos queriam ver, tocar e cheirar pra ver se sabiam dizer qual era.

Por fim, o tema do tabaco, item essencial naquilo que gostaria de chamar de "medicina indígena guarani mbya"2. Quando da segunda vez em que estive na aldeia, acontecia sua reinauguração, um evento para marcar a reconstrução da aldeia após o incêndio criminoso que ocorreu em meados de julho de 2008 e transformou a maioria (senão todas) das casas em cinzas.. Levei um saquinho de fumo "trevo" pra ver se conseguia trocar pelo fumo deles, mais natural, composto por folhas colhidas dos pés de tabaco que eles tinham plantado em Paraty Mirim. Logo que tive a chance, propus a troca para o Isaías (irmão do Darci), que prontamente aceitou. Daí por diante, toda vez que ia na aldeia tentava trocar o fumo que levava pelo fumo deles, e eles sempre aceitavam.

Posso afirmar, portanto, que estes três elementos de afinidade entre eu e eles funcionaram como facilitadores de minha entrada em campo e, por isso, ganharam, pelo menos para mim, o status de verdadeiras "ferramentas" de pesquisa. De modo que, quando comecei a perceber neles este devido valor, procurei tratá-los como caminhos de entrada no cotidiano das diversas aldeias em que visitava, pois como me disse o Carlinhos (colega do PPCIS - UERJ), "a gente entra pela porta que o povo abre para nós”.

Assim, quando comecei a perguntar se eu podia participar, algum dia, do ritual na casa de reza, as primeiras respostas eram meio evasivas, de modo que só me senti à vontade para entrar quando o próprio Darci me autorizou. A partir do que me falaram, não era tão rara a presença de um jurua (branco) na casa de reza, disseram que outras pessoas "de fora" já tinham ido lá para conhecer e participar, etc. Mas, ao meu ver, com a assiduidade a qual me dediquei ao ritual, creio que foram poucos.

E não apenas minha presença reafirmava o caráter de minha participação, mas também, e principalmente, minha disposição em fumar o cachimbo (pita petyngua) e dançar (jeroky). Assim, a minha identificação com o tipo de ritual praticado ali foi uma coisa muito pessoal, uma predileção minha, por assim dizer, e foi esta predileção que fez com que eu fosse cada vez mais reconhecido como alguém que estava ali com "sinceridade" e com "fé". Foi logo após a cerimônia de batismo na qual recebi meu nome indígena, quando o Darci 
explicava-nos o significado de nossos nomes. Especificamente para mim, ele disse, "a pessoa que tem poder espiritual ela vê as coisas a noite. A minha mãe vê quando a pessoa entra na casa de reza com fé e quando entra à toa, assim só pra ver".

\section{Como escrever sobre os Mbya Guarani}

Os Guarani formam uma grande família lingüística do tronco Tupi, porém, a depender da região e do ramo familiar, autodenominam-se de maneiras diferenciadas: Paí-Tavyterã, Aché ou Guayaki, Avá Katu, etc. Para os Guarani que habitam no Brasil é comumente aceita a subdivisão, proposta por Shaden (1974) e outros, em três grupos cujas línguas, embora com muitas semelhanças, diferem entre si: Mbya, Kaiowa e Nhandéva. Esta distinção aparece nas próprias designações utilizadas pelos Guarani para falarem de si ou dos "outros" guarani, quando podem aparecer outras denominações como por exemplo Tambeopé (o "verdadeiro" Mbya), ou Xiripa (como os Mbya se referem aos Nhandéva).

$\mathrm{Na}$ lista de povos indígenas do Brasil (ISA, 2001/ 2005) os Guarani aparecem com um asterisco, indicando que estão localizados em mais de um país. Estima-se que um total de $300.000^{4}$ indivíduos espalham-se por Bolívia, Paraguai, Brasil, Argentina e Uruguai. Para o Brasil o censo do ISA contou 45.787 indivíduos, a maioria (80\%, composta pelas parcialidades Kaiowa e Nhandéva) vivendo no estado do Mato Grosso do Sul. Os 20\% restantes seriam compostos pelos Mbya, tidos por Shaden (1974) como os únicos, dentre as três parcialidades, que continuam as migrações religiosas para o leste. As terras tradicionais que ocupam parecem indicar o sentido (direcional) do seu deslocamento histórico: localizamse nos estados de Rio Grande do Sul, Santa Catarina, Paraná, São Paulo, Rio de Janeiro e Espírito Santo, sendo a origem do movimento migratório comumente referida ao Paraguai ${ }^{5}$.

É interessante destacar que, além das três modalidades lingüísticas citadas, há ainda o guarani dito paraguaio, falado por cerca de quatro milhões de pessoas, e tida como a segunda língua oficial do Paraguai, depois do castelhano (Navarro, 2009). Também é notória a inclusão, desde 2007, do Guarani como idioma oficial do Mercosul, além do português e do espanhol ${ }^{6}$. Tais fatos nos fazem realizar que o que muitos pensam ser uma língua extinta é na verdade um idioma vivo e falado por milhões de pessoas, indígenas e não indígenas, e certamente, uma das línguas pré-colombianas que mais resistiu ao contato com as línguas "colonizadoras". 


\section{Ore reko, o "nosso costume": valores e identidade mbya}

A palavra reko, do subtítulo acima é derivada de teko, que é traduzida geralmente como "costume" ou "modo de vida". Embora o termo teko seja alvo de ampla e intensa investigação acadêmica, em meu trabalho de campo não observei o seu uso corrente, senão na forma de reko, ou seja, sempre atrelado à outra palavra, geralmente pronominal. Assim, falam ndereko, "seu costume" (ou "seu comportamento") e nhandereko, "nosso costume". A diferença entre ore reko e nhandereko é essencialmente gramatical: nhande significa um nosso inclusivo (isto é, inclui o interlocutor) e ore, o nosso exclusivo ${ }^{7}$.

O termo nhandereko é muito mais comum na literatura sobre os Guarani, porém ore reko me foi sugerido por Amarildo (18 anos), morador da aldeia de Niterói, que utilizou o termo em sua apresentação de seminário na I Conferência Nacional de Educação Escolar Indígena $(\mathrm{CONEEI})^{8}$, onde participou como professor (alfabetizador) representante de sua aldeia. Neste trabalho, Amarildo procura mostrar a situação da aldeia onde vive, dizendo que estão preservando o maior cemitério indígena (de sambaquis) do estado do Rio de Janeiro, que estão em luta contra os construtores de prédios (empresas imobiliárias) da região que pretendiam construir prédios no local, e também cita o fato criminoso, ocorrido em julho de 2008: "nossas casas e nossos pertences foram queimados por pessoas desconhecidas. Foi um momento de muito pavor intenso, difícil. Difíceis situações, mas conseguimos reconstruir oo casas e continuar nossa luta neste mesmo lugar". De uso corrente no texto é o termo luta, pois Amarildo afirma que ele e sua família estão em permanente luta para preservar sua cultura.

Aqui podemos nos aproximar um pouco mais desta cultura guarani, procurando captar seu significado primeiramente no texto de Amarildo. Ele continua do seguinte modo, "estamos assentados nesta área desde fevereiro de 2008, no local conseguimos construir nossas casas oo e casa de reza opy ‘ $\mathrm{i}^{9}$ onde continuamos a praticar nossas culturas”. Vemos então que ele entende cultura como algo plural, e associado à prática, ou seja, sua cultura não é uma só coisa, mas muitas, e estas coisas estão identificadas em práticas tais como, segundo o texto: "nossos rituais religiosos mbya mborai; praticamos nossas danças xondáro; os nossos artesanatos; a nossa pintura corporal; apresentação de nosso coral ao público”. Todos estes elementos fazem parte da vida na aldeia e são, por isso, passíveis de serem 
encapsulados no termo cultura guarani, embora possuam pesos e funções diferentes na vida social da comunidade.

Neste sentido gostaria de observar que durante o trabalho de campo reparei que certos adereços rituais apenas eram utilizados quando na presença de jurua (brancos), em dias de recepção na aldeia, tais como cocares de pena. Por isso sugiro que podemos pensar a descrição de Amarildo como gradativa, ou seja, ela possui um gradiente que, do ponto de vista dos valores guarani, vai de "dentro" (cantos religiosos mborai) para "fora" (apresentação do coral ao público). Os mborai (cantos melódicos, sem letra) apenas são executados dentro da opy (casa de reza) pelo rezador num clima de solenidade e concentração, jamais são executados em público. Já a apresentação do coral de hinos cantados em guarani, embora aconteça às vezes dentro da opy, é a forma principal, segundo me falou Amarildo, de introduzir a cultura guarani para o jurua ${ }^{10}$.

Pissolato, em seu trabalho, chamou a atenção para uma certa orientação geral dos autores que se dedicaram a refletir sobre o termo teko isoladamente, tratando-o como um sistema dado, que engloba tanto as práticas religiosas como uma certa ética do agir e da vida social, ambos legados dos antepassados. Nas palavras da autora, "mover-se na Terra relaciona-se à compreensão sobre seus ritmos cíclicos, à necessidade de pôr em funcionamento a rede de sociabilidade mbya e ao cumprimento de uma orientação religiosa (Pissolato, 2007, pp. 110 - 111)”. Assim, há uma tendência em pensar o teko como algo que, ao mesmo tempo, fundamenta e direciona a busca Guarani por novos territórios, nos quais o dito "modo de ser" possa atualizar-se. Pissolato segue explicando que:

(...) $\mathrm{Na}$ experiência das populações guaranis contemporâneas, em que problemas como o da terra tornam-se prementes, envolvendo negociações constantes com instâncias diversas de representação 'do jurua', o teko, ou, como se ouve muitas vezes, o nhandereko (...) tende a opor-se ao 'sistema do jurua', e o tekoa torna-se um modo usual de referência à 'aldeia', isto é, determinada área de ocupação entendida como dotada de condições fundamentais à reprodução do teko (Pissolato, 2007, pp. 108 109).

De acordo com a autora, há uma estreita ligação entre o "modo de ser" ou "costume" próprio dos Guarani e o território no qual ele vai efetivamente pôr-se em prática, e é bastante ilustrativo desta relação o termo tekoa, usualmente traduzido para o português (pelos Mbya) como "aldeia". Aliás, a maioria das aldeias mbya tem seu nome iniciado pela palavra tekoa, como por exemplo Tekoa Mbo`y Ty ou Tekoa Arandu Mirim. 
Podemos relacionar esta idéia com o texto de Amarildo, na medida em que ele parece sugerir um gradiente de sentido (de "dentro" para "fora") para os valores dos elementos com os quais objetivou descrever a cultura guarani, e ainda utiliza esta descrição para justificar a luta de sua família para manter o território (isto é, a aldeia, tekoa), enquanto empresas imobiliárias fazem pressão para que eles abandonem o local. É preciso, portanto, explicar melhor o que é este gradiente ao qual me refiro, e porque é importante entender o texto de Amarildo deste modo.

Voltando a ele resumidamente, Amarildo afirma que as culturas Guarani são: cantos religiosos mborai: danças, xondáro; artesanato; pintura corporal e por fim apresentação do coral ao público. Como já foi falado acima, o mborai é a própria reza, e é apenas executado neste contexto e dentro da opy. A dança xondáro acontece quase sempre durante o ritual diário, porém, quando de apresentações ao público, é executada em palcos ou no pátio da aldeia. Possui um clima de descontração, e os participantes se divertem durante sua execução. O artesanato é de uso comum entre os Mbya (colares, pulseiras) porém o investimento no feitio das peças, na maior parte das vezes, objetiva a venda para os jurua que visitem a aldeia $^{11}$. A pintura corporal, embora usada no dia-a-dia, sem que haja uma "regra fixa" para isso $^{12}$, é alvo de maior investimento nos dias de apresentação ou recepção do público, ocasião em ela se estende até os jurua (brancos) que estiverem dispostos a ter parte de seus corpos cobertos com tinta de urucum e jenipapo. O último fator, como já foi dito, é um modo fundamental de apresentar a cultura guarani para o público jurua, e, embora o coral também cante dentro da opy, parece que sua função principal reside mesmo na apresentação.

Assim, as culturas guarani, conforme referência de Amarildo, são as práticas que as designam, e junto com a língua formam o que ele chamou de ore reko (nosso costume exclusivo), termo que, sugiro, se aproxima mais da nossa idéia (ocidental) de cultura. Como mostramos, existe um gradiente nas práticas culturais, conforme Amarildo as enumerou, e tal gradiente nos leva a entender estas culturas de acordo com os valores atribuídos pelos próprios Guarani. Valores religiosos, estéticos e de mercado convergem para a elaboração de uma fronteira entre o ser guarani e o não sê-lo.

\section{Sociabilidade e mborayu: o "ponto de vista" vindo da divindade}


Diante de uma ocupação guarani levada a cabo por uma família extensa (que engloba quatro gerações) em plena "área nobre" da cidade de Niterói, podemos nos perguntar: porque a mobilidade Guarani possui características tão singulares? Isto é, o que faz a família se manter unida e deste modo pretender se deslocar e formar novas aldeias, algo que envolve conflitos com órgãos do governo a até com entidades privadas? Podemos começar a caminhar em direção a uma resposta ao refletirmos sobre uma frase dita sobre o Darci, quando explicava para um casal de jurua (brancos) em visita à opy de sua aldeia porque entravam todo dia para rezar: "a gente vai todo dia, porque assim mantém a cultura também, pois o conhecimento vem do fortalecimento".

Fortalecimento em Guarani Mbya, e em contextos relacionados à religião, se diz mbaraete, e significa “fortalecimento espiritual”. Assim, numa espécie de inversão do esquema ocidental de aprendizado, ensinamento - aprendizado - conhecimento, Darci afirma que é o fortalecimento espiritual e as práticas que ele envolve (rezar, dançar, fumar o cachimbo, tudo isso dentro da opy) que trazem o conhecimento. Tal afirmação parece ir ao encontro do que Miguel (26 anos) e vários outros Mbya me falaram sobre o tornar-se pajé: "você não aprende de ninguém, é só Nhanderu que ensina mesmo". O que me parece fundamental nestas idéias é a noção de que o conhecimento pode ser proveniente de outras fontes, nas quais nada está escrito, mas se pode sentir enquanto uma presença ou uma força em ação. Reside aí, ao meu ver, um dos pontos principais da religião mbya, a saber, a possibilidade de uma comunicação direta com a divindade através do uso do cachimbo (petyngua), da reza-canto (mboraî) e da dança (jeroky).

Aliás a própria cura efetuada pelo pajé não é, na realidade, um trabalho exclusivo dele, mas como me disse Alzira (atual pajé da aldeia de Paraty Mirim, Paraty-RJ) "não sou eu, é o Nhanderu que cura". A afirmação está de acordo com o que Pissolato ouviu de Candinho, pajé centenário, que atuava na mesma aldeia antes de seu falecimento: "por si mesmo ninguém faz (...) Se Nhanderu não mostra, não quer" (Pissolato, 2007, p.345). Podemos ver que o poder nunca é atribuído ao indivíduo, ainda que este excerça o papel de especialista, mas sim à uma exterioridade divina que, embora possa se fazer ouvir por qualquer membro da sociedade mbya que saiba escutar suas mensagens, seleciona alguns concedendo-lhe um dom espiritual através da revelação.

No caso da Lídia, como vimos acima, apenas foi em Niterói que ela começou a exercer de forma sistemática as funções de pajé e líder espiritual. Vale entrar um pouco mais 
na sua história, conforme me contaram Miguel (26 anos) e Luciana (15 anos e neta da Lidia). Começaram dizendo que "a revelação da Lídia foi assim" e aí falaram que ela bebia e fumava muito, só que de um dia para o outro começou a beber e a vomitar tudo, passar muito mal. Neste ponto Miguel disse, "é assim mesmo, você já sabe que Nhanderu tá te chamando". Quando estavam em Paraty Mirim ainda, eles fizeram uma casinha na parte de baixo da aldeia, onde moravam, para ela rezar, aí "ela pegou petyngua (cachimbo) e começou”. Porém disseram que só em Niterói é que ela começou a curar e a fazer nimongarai (batismo). Aqui fica clara a estreita ligação entre o deslocamento do grupo e a revelação da pajé.

O mesmo Miguel, falou-me que "tão importante para nós quanto a opy é plantar. Porque quando você planta assim, você não planta só para você, você planta pra toda a comunidade, e Deus tá vendo isso. Você vai ficar forte, sua família também, com saúde". Se, como explicou o Darci, o conhecimento vem do fortalecimento espiritual, e este de contextos em que o indivíduo se põe em contato direto com a divindade, o ato de plantar para a comunidade também implica no fortalecimento do sujeito, pois "Deus está vendo o que você está fazendo". E o que o indivíduo faz de tão importante é justamente pensar no grupo como um todo e não apenas em si mesmo. Creio que é esta qualidade que Deus irá recompensar com o fortalecimento aquele que trabalha e ajuda na plantação.

Podemos entrever, em ambas as falas, uma ligação estreita entre o fortalecimento espiritual, algo provindo de Nhanderu (Deus), e o trabalho que se faz para o "outro" (no caso, um outro habitante da mesma aldeia) ou mesmo para todo o grupo. Em relação ao trabalho (na lavoura, construção, artesanato, etc), reparei que é bastante raro ver um indivíduo se isolando dos outros em busca de "privacidade" para realizar sua tarefa. Pelo contrário, os momentos são sempre compartilhados e o trabalho é, na maior parte das vezes, realizado para os outros (ou, talvez seja melhor, para todos) e não para si mesmos. É, ao meu ver, essencial para a família, esta rede de compartilhamento, pois foi só quando comecei a me tornar parte dela, que pude vivenciar aspectos mais profundos do cotidiano das aldeias.

A partir de leituras anteriores sobre religiosidade e xamanismo mbya guarani (Cadogan apud Meliá, 2005; H.Clastres, 1978; Fausto, 2007) tomei ciência de uma noção de reciprocidade e amor ao próximo que já tinha ouvido falar durante o trabalho de campo, por exemplo quando falavam que "o pajé não pode ficar bravo com ninguém, mesmo se outra pessoa estiver brava com ele" ou que "o pajé não pode fazer mal a ninguém, a planta, bicho, não pode caçar nem fazer trabalho pesado". Trata-se do conceito de mborayu, traduzido 
comumente como amor (Cadogan apud Meliá, 2005). O conceito mbya guarani de "amor ao semelhante" (mborayu) será melhor compreendido se levarmos em conta a noção dupla, ou polarizada da alma humana.

$\mathrm{Na}$ concepção mbya de alma humana encontramos dois pólos opostos, os quais podemos perceber através de determinadas disposições do indivíduo. A "porção divina da alma" (Cadogan, apud Meliá, 2005), ou nhe'e, é originária de Nhanderu, e revelada ao indivíduo pelo pajé, durante o ritual de nimongarai. É responsável, como me explicou Santo (59 anos, morador da aldeia do Mamanguá, Paraty-RJ), pela capacidade de adquirir a sabedoria, ficar animado, trabalhar, se levantar, etc. Num extremo, é esta porção da alma que é capaz, justamente por sua origem e qualidades, de levar o indivíduo a alcançar a "terra de Nhanderu", algo que se faz "com este corpo mesmo", como afirmou Miguel, da aldeia de Niterói.

A porção dita "telúrica" (Pellon, 2008) da alma, denominada pelos Mbya de teteregua (do corpo), ocasionaria estados de preguiça, desânimo, tristeza, etc. Em vez de ter uma origem divina o teteregua é proveniente do anhã (diabo), conforme afirmaram Amarildo, Santo e outros Mbya com quem conversei sobre o assunto. No extremo oposto da possibilidade transcedente do nhe'e, o teteregua pode fazer com que o indivíduo se transforme em bicho (jepota), literalmente, algo que é evitado através do uso petyngua (pelo próprio indivíduo, ou pelo pajé que o vai tratar), da dança durante as rezas e outras atitudes. Conforme observa Luiz Pellon, a partir de seu trabalho de campo com os Mbya da aldeia de Aracruz (ES), "desde cedo é ensinado ao jovem Mbya a necessidade de se dominar o poxy, o sentimento de cólera, através do desenvolvimento de suas qualidades espirituais, em detrimento das suas imperfeições mundanas” (Pellon, 2008, p.109).

Se existe uma polaridade entre "porção divina" e "porção telúrica" (e ela é bem real e palpável na experiência mbya) ela se manifesta justamente no corpo do indivíduo, de modo que a forma mais comum de explicar tanto uma como a outra, é através de estados que elas provocam no corpo humano (como ânimo, fortalecimento, ou tristeza, raiva). Foi definitivo para que eu percebesse esta centralidade do corpo para entender a concepção de alma mbya, quando certa vez perguntei a Joaquim (morador da aldeia de Niterói) sobre a possibilidade de se entrar na opy após ter bebido (álcool) durante o dia, fato que havia observado em outra aldeia mbya. Ao narrar o fato ressaltei que os indivíduos em questão haviam bebido, porém entraram na casa de reza com concentração, fumando petyngua e até rezando (cantando). A 
resposta de Joaquim foi que "se a pessoa entra sem bagunçar, com respeito, aí tudo bem, porque não pode julgar o corpo. A pessoa tem que entrar com o corpo que tem, pra fortalecer, pedir perdão. Se ele não entrar, quem perde é ele mesmo".

\section{Aldeia e cidade: experiências em trânsito}

As categorias acima e os conflitos que elas sugerem, como mencionado na introdução deste trabalho, aparecem nas falas dos sujeitos da pesquisa, e foi aí que primeiro vislumbrei a possibilidade de uma análise comparativa entre elas. Assim, Ivanildes (29 anos) Agente Indígena de Saúde, indicou como fator negativo da aldeia de Paraty Mirim (onde reside) a proximidade com a cidade (Paraty-RJ), "aqui pega muita influência da cidade, tá muito perto".

Porém, ao mesmo tempo que a proximidade com a cidade pode atrapalhar por este excesso de influência, citado por Ivanildes, a mesma não possui queixas acerca da escola municipal que frequenta, localizada na cidade de Paraty. Disse ela que no colégio "o pessoal respeita muito, não tenho do que reclamar". Embora a presença dos Guarani nas escolas de Paraty ou Angra seja bem escassa, Ivanildes frequenta esta escola com um interesse específico: formar-se no Ensino Fundamental, para poder fazer o curso de AIS (Agente Indígena de Saúde). Ainda que na aldeia de Paraty Mirim tenha um colégio com professor indígena, este só vai até a quarta série, portanto, para os que querem chegar a ocupar cargos como de AIS ou Professor, torna-se necessário recorrer aos recursos educacionais do jurua (brancos), isto é, as escolas públicas da cidade mais próxima.

Sobre a mesma aldeia, o pajé e benzedor Aparício comentou que, dentre três fatores que ele achava ruim do lugar, um era a proximidade da cidade, pois "quem tem vício vai na cidade e traz a bebida muito fácil". O mesmo, porém, ao ser perguntado porque não foi residir na aldeia do Mamanguá (já que tinha sido convidado), respondeu que "o acesso lá é muito difícil, só por água (...) Se tiver alguma emergência e tem que levar a pessoa logo,é difícil". Vemos que entre uma aldeia excessivamente perto da cidade e outra cujo acesso é dificultoso e cansativo, Aparício vai ficando na primeira, enquanto reúne forças para fundar uma nova tekoa (aldeia), na Praia Brava da Trindade (Paraty - RJ), que disse ser o seu objetivo $^{13}$. 
Deslocando a narrativa para um pouco mais ao norte do estado, a chegada de uma tribo indígena em Niterói causou grande impacto na opinião pública, principalmente entre os moradores de Camboinhas, onde os Mbya se instalaram. Em notícia publicada no site nitdeal (site de notícias de Niterói) em 16/05/08 um médico (de 53 anos) morador do bairro afirmou indignado que "eles nadam pelados, as mulheres andam com os seios de fora, enfim, vivem da forma deles, sem se preocupar com nossa presença. Porém, eles agora moram no meio urbano" ${ }^{\prime 14}$. Posteriormente habitantes da aldeia justificaram publicamente a afronta, dizendo que somente os menores nadavam pelados, porém a questão exige uma análise mais cuidadosa.

Para o médico, os "hábitos indígenas" causariam constrangimento aos moradores de Camboinhas, e é notório o modo como ele encerra seu comentário: "eles moram no meio urbano agora". Assim, agora eles devem se comportar de maneira "civilizada", pois Camboinhas não é nenhuma floresta, é sim um bairro numa nobre área urbana de Niterói (como tratada em grande parte das notícias). O que vemos cair sobre os Guarani aqui é o peso de uma idéia pré-concebida dos significados que envolvem a categoria tão conhecida de "índios". O morador de Camboinhas espera e acha que "índio" é alguma coisa, porém, ao se deparar com esta coisa real (que é obviamente diferente do que ele achava que era) a relação não deu conta de atualizar a idéia, por isso os conceitos antigos acabaram por se impor à realidade.

De um ponto de vista mais geográfico talvez, podemos olhar para o "conflito" entre os moradores de Camboinhas e a aldeia indígena que ali se instalou através de uma percepção das relações que cada um dos grupos mantém com o lugar que ocupam. O que gostaria de destacar aqui é que o modo de ser mbya guarani, com suas concepções de mundo e de alma humana, implica a fabricação de um corpo específico e diverso daquele que a sociedade jurua (brancos, aqui representada pelos moradores de Camboinhas) produz para seus membros. Corpos diferentes criam diferentes laços com o lugar, e com ele mantém relações distintas, apropriando-se do espaço circundante de maneiras específicas: "o lugar é a porção do espaço apropriável para a vida - daí a importância do corpo e dos sentidos. (...) Significa que nossa existência espaço-temporal, tem uma corporeidade, pois agimos através do corpo na medida em que é ele que nos dá acesso ao mundo" (Carlos, 2004, p.51)

Assim, temos privilegiado a apresentação da religiosidade mbya guarani pois concebemos que é através dela que podemos compreender a noção de pessoa-alma-corpo que 
está envolvida na relação deste grupo com os lugares que ocupam. É através desta noção que podemos olhar para a reciprocidade/ sociabilidade entendo-a como um veículo que realiza em cada indivíduo as condições necessárias para a formação de uma tekoa (aldeia). No corpo (alma) ao qual forças exteriores vêm atuar encontramos uma tendência contrária ao corpo laico desejoso de estabelecer a consciência de sua própria presença transformando “ $a$ existência corporal em veículo de si mesmo, no limite, numa espécie de marketing privilegiado eu" (Sant'Anna, 2001, p.103). O que entra em conflito aqui também um código urbano de imperativo do individualismo com um código guarani que vai de encontro a ele.

A praia de Camboinhas corresponde, em alguns aspectos, aos "enclaves fortificados" propostos por Teresa Caldeira (1997, p.155-176). Primeiramente é um espaço de moradia de uma classe média para alta, como se pode observar pelo padrão das casas e prédios construídos no local. Segundo, que possui intenso monitoramento por câmeras e vigias de ruas, o que sugere uma preocupação com a violência. Terceiro que, ainda que não seja um espaço oficialmente fechado, circundado por muros, tal como os modelos analisados pela autora, a própria geografia da praia, rodeada por morros e florestas, funciona como um isolante natural: existe somente duas entradas para carros em Camboinhas, e as outras formas de se chegar à praia são, a pé (ou de canoa) atravessando o canal de Itaipu ou, no outro extremo da praia fazendo uma trilha desde Piratininga (outra praia da Região Oceânica de Niterói), ou então de barco.

Gostaria de chamar a atenção aqui para um outro aspecto dos "enclaves fortificados" que pode nos ajudar a compreender a reação negativa da população local em relação à ocupação indígena. Teresa Caldeira explica que "enclaves fortificados representam uma nova alternativa para a vida urbana dessas classes médias e altas, de modo que são codificados como algo que confere alto status. Em outras palavras eles repetidamente expressam a segregação social como um valor" (Caldeira, 1997, p.159).

Embora Camboinhas seja uma praia pública, bem como qualquer outra da Região Oceânica, ela pode ser freqüientada por todos, mas nem todos podem (refiro-me aqui ao poder econômico) habitá-la. Mansões e prédios construídos em áreas de restinga, passando por cima não só de preciosa parcela da biodiversidade local, mas também das leis de preservação ambiental, são coqueluches para uma prestigiosa elite que deseja uma moradia "com vistas para o mar". Alexandre (28) morador do bairro e colega de Niterói, disse-me certa vez, “ $a$ SOPRECAM (associação de moradores de Camboinhas) acha que aquilo lá é um 
condomínio!". A fala de Alexandre deixa claro o valor segregacional que paira na geografia e na organização social do bairro.

O que Oliven aponta em sua conclusão é que os processos sociais urbanos não podem ser analisados através de categorias analíticas fixas, pois não há uma escala de valores e nem uma sequência linear de fenômenos com os quais possamos mensurar os dados observados nos diferentes contextos (cf. Oliven, 2007, p.65). O que há é uma multiplicidade de processos,que podem ser diferenciados justamente nos pontos em que os grupos e indivíduos envolvidos estabelecem fronteiras entre si e os outros. Da mesma maneira Barth procura explicar a importância das relações dicotomizadas entre grupos étnicos, cujas distinções formam as bases de sistemas sociais abrangentes:

as distinções étnicas não dependem da ausência de interação (...) mas, ao contrário, são frequentemente a própria base sobre a qual sistemas sociais abrangentes são construídos. A interação dentro destes sistemas não leva a sua destruição (...): as diferenças culturais podem persistir apesar do contato interétnico e da interdependência entre etnias (Barth, 2000, p.26).

Desta forma, os Guarani Mbya, em relação com elementos "urbanos" ilustram esta interatividade entre sistemas e grupos étnicos distintos, num processo que passa longe de poder ser chamado de "aculturativo", mas que traz elementos capazes de categorizar os indivíduos de um grupo étnico, de acordo com valores do outro grupo. O modo específico como se relacionam com estes elementos e os significados implicados é que devem ser analisados criticamente. A "cidade" já conhece os Guarani de longa data, os moradores de Camboinhas, ao que parece, é que ainda não conheciam.

\section{Conclusão}

As idéias que tentei trazer à tona neste trabalho nos revelam que a experiência indígena na cidade não implica necessariamente uma fragmentação do grupo e de sua cultura, mostrando que, no que diz respeito ao caso estudado, os Guarani Mbya souberam muito bem se adaptar à manipulação de identidades que é inerente ao modo de vida urbano (Cardoso de Oliveira, 2006). A relação algo solene e íntima que guardam no que diz respeito à sua religiosidade em oposição aos adereços utilizados de forma criativa e estratégica quando da presença de não-índios na aldeia indica um jeito indígena de vivenciar a experiência urbana. 
Esta vivência, sentida e organizada no corpo indígena e sua correlata noção de pessoa/ alma/ nome, se traduz num modo específico de se relacionar com o lugar, diferente dos modos associados ao não-índio, cujo código de urbanidade inclui o individualismo, o aproveitamento dos espaços para fins imobiliários, etc. Uma aldeia guarani com seu imperativo de vida familiar e seu código de reciprocidade vai ao encontro desta lógica urbana, ao mesmo tempo em que aprende a se relacionar com ela.

\section{REFERÊNCIAS BIBLIOGRÁFICAS}

BARTH, Fredrik. O guru, o iniciador e outras variações antropológicas. Rio de Janeiro: Contra-capa livraria, 2000

CADOGAN, Léon. Ayvu Rapyta: textos místicoa guaraníes. Adaptado por MÉLIA, Bartolomeu. $1^{a}$ edição, Córdoba, Universidade Católica de Córdoba, 2005.

CALDEIRA, Teresa Pires do Rio. Enclaves Fortificados: a nova segregação urbana. In.: Novos Estudos, CEBRAP. No 47, MARÇO, 1997.

CARLOS, Ana Fani Alessandri. O espaço urbano: novos escritos sobre a cidade. São Paulo, Contexto, 2004.

CLASTRES, Hélène. A terra sem mal. São Paulo, Editora Brasiliense, 1978.

FAUSTO, Carlos. If god were a jaguar. Cannibalism and christianity among the Guarani (16th - 20th century). In: (orgs) FAUSTO, Carlos \& HECKENBERGER, Michael. Time and memory in indigenous Amazonia: Antropological perspectives. University Press of Florida. 2007.

NAVARRO, Eduardo de Almeida. O domínio da língua castelhana sobre o guarani paraguaio. In: http://www.filologia.org.br/revista/artigo/10(29)09.htm

OLIVEN, Ruben George. A antropologia de grupos urbanos. Petrópolis, RJ. Vozes, 2007.

PISSOLATO, Elizabeth. A duração da pessoa: mobilidade e parentesco e xamanismo mbya (guarani). São Paulo, Editora UNESP: ISA; Rio de Janeiro, NuTI, 2007.

SHADEN, Egon. Aspectos fundamentais da cultura guarani. São Paulo, EPU, editora da Universidade de São Paulo, 1974.

VERA RETE, Amarildo Nunes. Ore Reko, o nosso costume. Apresentação de seminário no I CONEEI (Conselho Nacional de Educação Escolar Indígena), etapa Sul. Paraná, 2009.: 
- Folheto de divulgação da campanha Povo Guarani, Grande Povo. Material elaborado pela Comissão de Lideranças e Professores Indígenas e Conselho Indigenista Missionário (CIMI) regionais Sul e Mato Grosso do Sul. 2007.

\author{
- Povos Indígenas do Brasil 2001 - 2005/ [editores gerais Beto Ricardo e Fany Ricardo]. \\ Instituto Socio Ambiental, são Paulo, 2006.
}

\footnotetext{
${ }^{1}$ Outras duas coisas trabalharam a meu favor, e dizem respeito fundamentalmente à determinadas disposições minhas: disposição para ajudar, seja trazendo sementes, seja participando em atividades de construção que eles estivessem envolvidos no momento em que eu chegava na aldeia; disposição para dançar, tocar e cantar, a partir do momento em que passei a freqüentar a opy (casa de reza).

2 Já ouvi o Darci se referir à "medicina guarani”, mas o termo me surgiu anteriormente à guisa da noção indígena de que há uma doença do índio e uma doença do branco. A primeira só pode ser tratada pelo pajé e a segunda, pelo médico e pela equipe de saúde indígena. Tal diferenciação apareceu-nos pela primeira vez numa palestra de Tonico Kaiowa, numa mesa redonda na UFF, sobre saúde indígena. Também é explicada detalhadamente no livro da Elisabeth Pissolato (2007, p.202 - 03).

${ }^{3}$ A D.Lidia é a pajé, líder espiritual da aldeia de Niterói. É também a mulher mais velha, e junto com o S.Pedro, forma o casal cabeça, pais ou avós da maioria dos moradores. Aliás, o termo de referência mais comum (utilizado por filhos, netos e até bisnetos) para este casal é papai, para o S.Pedro, e mamae, para a D.Lidia.

${ }^{4}$ Fonte: Folheto de divulgação da campanha "Povo Guarani, Grande povo", material produzido em 2007 pela comissão de lideranças e professores Guarani Kaiowa e Conselho Indigenista Missionário regionais Sul e Mato Grossodo Sul.

${ }^{5}$ Esta referência ao Paraguai apareceu no trabalho de campo tanto na forma mítica como na prática. Miguel, da aldeia de Niterói, ao contar-me a "história do Sol", referiu-se ao Paraguai como o lugar onde seria o centro, e a origem do mundo. Da mesma forma, dizem sobre uma antiga líder espiritual, D.Maria Tataxi, que, nos anos 1940-50, andou pela maioria das aldeias litorâneas, indo terminar sua caminhada no ES, que "ela veio andando desde o Paraguai".

${ }^{6}$ Conforme fonte em: http://www.brasilescola.com/geografia/mercosul-paises-integrantes.htm.

7 A referência lingüística aqui são as aulas de Guarani Mbya ministradas pela professora lingüista Ruth Montserrat para os estagiários do Pró-Índio, UERJ, no primeiro semestre de 2007. Por gentileza da professora e dos coordenadores do Pró-Índio (Valéria e Bessa) pude assistir às aulas. Ali se deu meu primeiro contato com a língua mbya. Porém esclareço que o aprendizado maior se deu mesmo durante o trabalho de campo, onde depois de algum tempo começou um investimento da parte dos Guarani em ensinar-me.

${ }^{8}$ Especificamente, Amarildo apresentou seu trabalho na etapa Regional Sul (Paraná, Rio de Janeiro, Rio Grande do Sul, Santa Catarina e São Paulo) da Conferência Nacional, que acontecerá em setembro de 2009, em Brasília - DF. Assim, o termo ore, em vez de nhande, se justifica, segundo me explicou, porque o trabalho foi apresentado para uma platéia composta por outros Guarani e até outras etnias indígenas (como Kaingang). Assim, Amarildo tratava de destacar que aquela era a nossa luta, o nosso jeito, dali da sua aldeia, não de outras quaisquer.

${ }^{9}$ A presença do - ' $i$ indica o diminutivo, como em português -inho (a). Dizer opy' $i$ seria então o equivalente a dizer "casinha de reza", ou seja, é um modo talvez mais afetivo de se referir à opy. Reparei que é de uso muito comum entre os Mbya, inclusive de outras aldeias.

${ }^{10}$ Isso ficou claro para mim quando ele me falou que no CONEEI a apresentação do Guarani foi "jurua purinho", isto é, alguém subiu ao palco e só falou sobre a cultura guarani. Para ele tinha que ter tido a apresentação do coral.

${ }^{11}$ Reparei que os Mbya reconhecem no estilo de fazer as peças (motivos, cores, modo de aproveitar os recursos naturais, como as palhas de taquara) um jeito emblematicamante seu. $\mathrm{O}$ mesmo pode ser dito para quem adquire as peças (os brancos) visando utilizá-las como artigo decorativo em suas casas, onde ela adquire o valor de um objeto "autenticamente" indígena em exposição.

${ }^{12}$ Certa vez estive presente numa aula de Guarani ministrada por Tonico e Amarildo para duas senhoras jurua, alunas regulares do Darci, em suas aulas de Cultura Guarani. Uma delas perguntava insistentemente sobre as
} 
regras de casamento, se o homem tinha que ir viver com os sogros, ou o contrário, etc. Apesar de terem dado uma resposta que satisfez minimamente a inquisidora naquele momento, posteriormente, quando conversávamos sobre o ocorrido, Amarildo comentou comigo: “não tem regra fixa, né cara!". O episódio todo nos chama a atenção para a necessidade de estarmos abertos, no trabalho de campo, para experiências inesperadas pois assim nos aproximamos da característica fluida da vida, afastando-nos da rigidez de regras preconcebidas e coisas afins.

${ }^{13}$ Enquanto escrevia este trabalho, Aparicio já se mudou de Paraty Mirim para Araponga, onde residiu por alguns meses, tendo formado uma nova família no local, já que casou-se com uma das filhas do cacique Augustinho. Dali, já se mudou novamente, sendo que os moradores do lugar não sabem indicar seu próximo destino. Dizem que provavelmente foi para São Paulo onde possui familiares.

${ }^{14}$ Fonte: http://www.nitideal.com.br/newnit/index_int.php?act=5\&id=2474 